San Jose State University

SJSU ScholarWorks

Master's Theses

Master's Theses and Graduate Research

1993

\title{
Identification of health related learning needs following automatic internal cardioverter defibrillator implantation
}

Laura J. Val

San Jose State University

Follow this and additional works at: https://scholarworks.sjsu.edu/etd_theses

\section{Recommended Citation}

Val, Laura J., "Identification of health related learning needs following automatic internal cardioverter defibrillator implantation" (1993). Master's Theses. 654.

DOI: https://doi.org/10.31979/etd.fe36-wrz2

https://scholarworks.sjsu.edu/etd_theses/654

This Thesis is brought to you for free and open access by the Master's Theses and Graduate Research at SJSU ScholarWorks. It has been accepted for inclusion in Master's Theses by an authorized administrator of SJSU ScholarWorks. For more information, please contact scholarworks@sjsu.edu. 


\section{INFORMATION TO USERS}

This manuscript has been reproduced from the microfilm master. UMI films the text directly from the original or copy submitted. Thus, some thesis and dissertation copies are in typewriter face, while others may be from any type of computer printer.

The quality of this reproduction is dependent upon the quality of the copy submitted. Broken or indistinct print, colored or poor quality illustrations and photographs, print bleedthrough, substandard margins, and improper alignment can adversely affect reproduction.

In the unlikely event that the author did not send UMI a complete manuscript and there are missing pages, these will be noted. Also, if unauthorized copyright material had to be removed, a note will indicate the deletion.

Oversize materials (e.g., maps, drawings, charts) are reproduced by sectioning the original, beginning at the upper left-hand corner and continuing from left to right in equal sections with small overlaps. Each original is also photographed in one exposure and is included in reduced form at the back of the book.

Photographs included in the original manuscript have been reproduced xerographically in this copy. Higher quality $6^{\prime \prime} \times 9^{\prime \prime}$ black and white photographic prints are available for any photographs or illustrations appearing in this copy for an additional charge. Contact UMI directly to order.

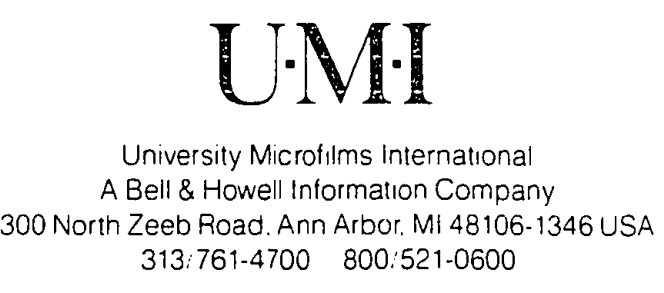


Identification of health related learning needs following automatic internal cardioverter defibrillator implantation

Val, Laura J., M.S.

San Jose State University, 1993 


\title{
IDENTIFICATION OF HEALTH RELATED \\ LEARNING NEEDS FOLLOWING \\ AUTOMATIC INTERNAL CARDIOVERTER DEFIBRILLATOR \\ IMPLANTATION
}

\author{
A Thesis \\ Presented to \\ The Faculty of the Department of Nursing \\ San Jose State University
}

In Partial Fulfillment

of the Requirements for the Degree

Master of Science

By

Laura J. Val

December, 1993 


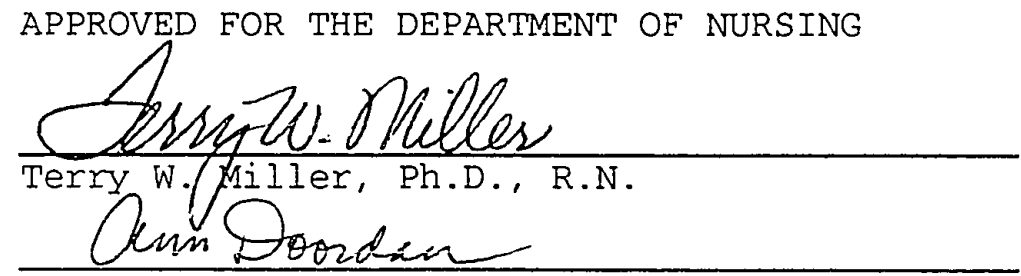

Ann Doordan, Ph.D., R.N.

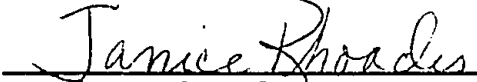

Janlce Rhoades, D.N.S., R.N.

APPROVED FOR THE UNIVERSITY

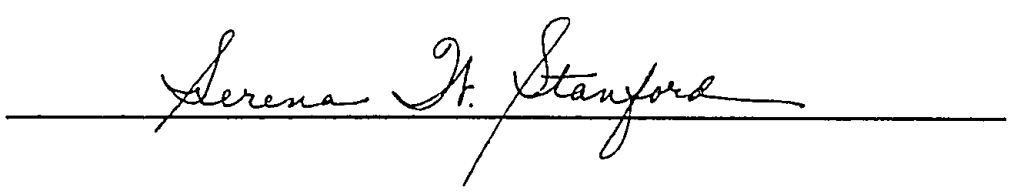




\section{ABSTRACT \\ IDENTIFICATION OF HEALTH RELATED \\ LEARNING NEEDS FOLLOWING \\ AUTOMATIC INTERNAL CARDIOVERTER DEFIBRILLATOR IMPLANTATION}

by Laura J. Val

This exploratory study identified health related learning needs of automatic internal cardioverter defibrillator ( $A I C D$ ) recipients following their discharge home. The Cardiac Patient Learning Needs Inventory (CPLNI) and a structured Interview Guide were the data collection methods. Thirty-two AICD recipients participated in the study. Random telephone sampling of 16 of the recipients was used to determine the optimum time for patient teaching.

Data from the Interview Guide indicated health related learning needs fell into three categories: (a) general health related progress, (b) physical activity and limitations, and (c) fears, anxieties, and anger. Data from the CPLNI indicated it was at least moderately important to know about all areas of their care. The highest mean scores, indicating important information for the recipients, were in the categories on "medication," "activities," and "when to call the doctor." Telephone interviews indicated the optimum time for patient teaching was between two and four weeks after discharge. 


\section{ACKNOWLEDGEMENTS}

I would like to thank my children, Jodi and Jamie, who I hope will someday understand why their mother chose to return to school after all those years. I hope they will appreciate, as I do, the importance of a good education. I would also like to thank my mother, Dottie, who has always believed in me and encouraged me throughout my life. 
TABLE OF CONTENTS

Page

LIST OF TABLES . . . . . . . . . . . . . . . . . . . vii

Chapter

1. INTRODUCTION . . . . . . . . . . . . . . . . 1

Statement of the Problem . . . . . . . . 3

Purpose . . . . . . . . . . . . . . . . . . . 5

Definition of Terms . . . . . . . . . 5

Objectives of the Study . . . . . . . . . 6

Question . . . . . . . . . . . . . 7

Assumptions . . . . . . . . . . . . . . 7

Research Design . . . . . . . . . . . 7

Scope and Limitations . . . . . . . . . . 9

2. CONCEPTUAL FRAMEWORK AND REVIEW OF RELATED

LITERATURE . . . . . . . . . . . . . . . . 11

Conceptual Framework . . . . . . . . . . 11

Review of Literature . . . . . . . . . 14

3. METHOD . . . . . . . . . . . . . 20

Research Design . . . . . . . . . . 20

Subjects.............. . . 20

Instruments . . . . . . . . . . . . . . . 21

Data Collection Procedures . . . . . . . 24

4. FINDINGS . . . . . . . . . . . . . . 27

Interview Guide Responses . . . . . . . . 27

CPLNI Responses . . . . . . . . . . . 36 


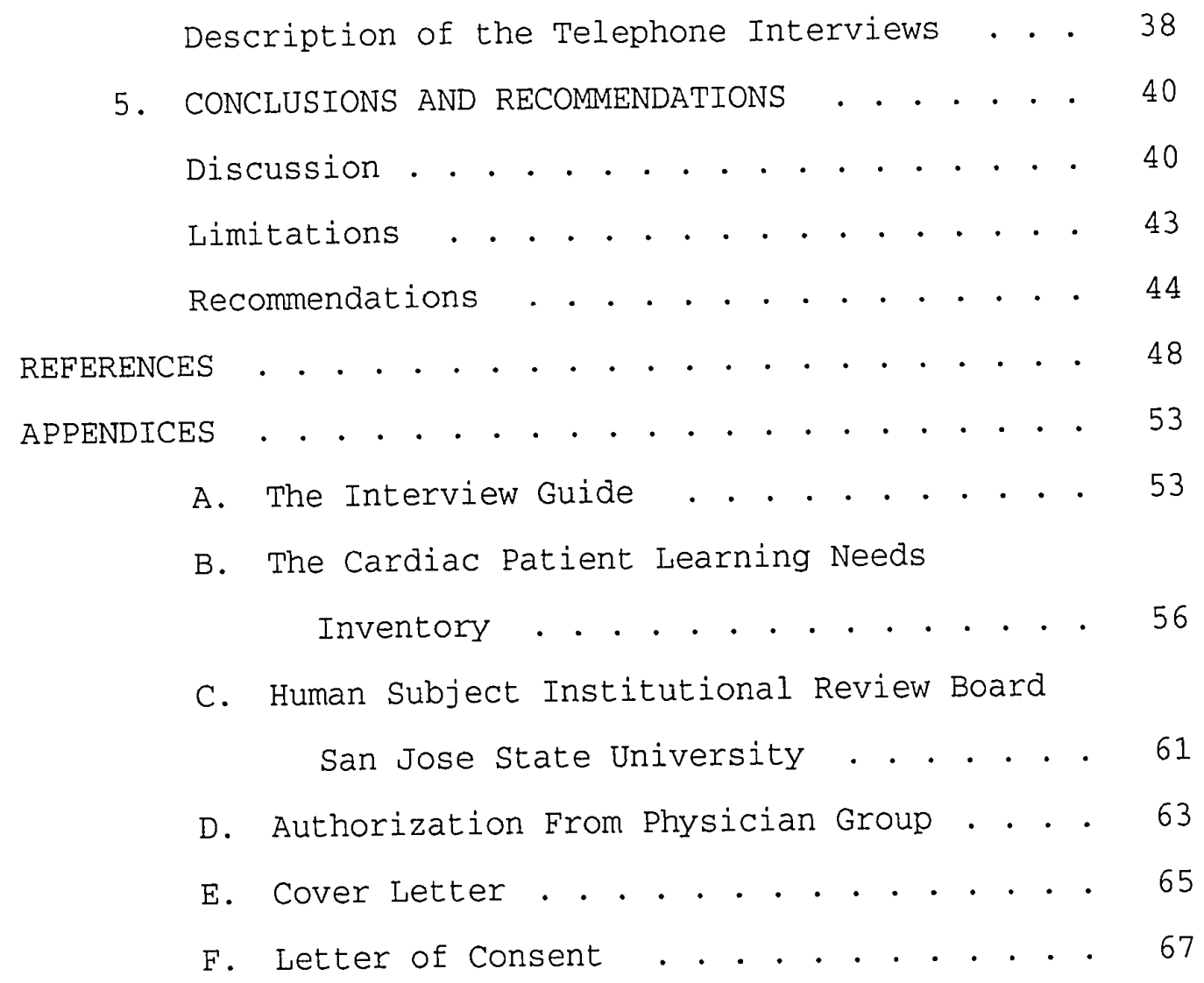




\section{LIST OF TABLES}

Table Page

1. General Health Related Progress . . . . . . 29

2. Expressed Anxieties, Fears, or Anger . . . . 31

3. Reasons for Anxieties, Fears, or Anger . . . 33

4. Concerns Regarding Exercise/Activities . . . 34 


\section{Chapter 1}

\section{INTRODUCTION}

The automatic internal cardioverter defibrillator (AICD) has become a clinical solution for reducing the risk of sudden death for patients with malignant and lifethreatening ventricular dysrhythmias. Since 1980 when the first human implant of the AICD was performed at Johns Hopkins University Hospital in Baltimore, over 15,000 devices have been successfully implanted (Teplitz, 1991).

Patients generally are identified as being at high risk of dying from a lethal dysrhythmia before being considered as a candidate for an AICD implantation. All patients elected to receive the AICD have survived one or more episodes of sudden cardiac death resulting from ventricular tachycardia (VT) or ventricular fibrillation (VF). These patients have greater than a $70 \%$ chance of clinical recurrence. When treated with antidysrhythmic medications, the most common method in preventative treatment, these individuals still have an extremely high one-year mortality rate. This mortality rate ranges from $27 \%$ to as high as $66 \%$ (Hillis, Firth, Winniford \& Willerson, 1988). In comparison, the patients in whom the AICD is implanted have a one year mortality rate from cardiac dysrhythmias of less than 2\% (Hurst \& Schlant, 1990).

The defibrillator itself is a titanium pulse generator 
currently costing about $\$ 17,000$ (R. H. Mead, personal communication, March 1, 1993). This $0.25 \mathrm{~kg}$. device contains the sensing circuitry for detection of heart rate and rhythm. This electronic circuitry can detect dysrhythmias and initiate the charging and firing of the defibrillator through two pairs of bipolar electrodes attached directly from the generator to the heart muscle. The surgical approach for electrode placement may be either subxiphoid, subcostal, left anterolateral or through a median sternotomy (Teplitz, 1991). On certain patients, leads may be placed nonsurgically through a transvenous route, thereby avoiding major surgery and many of the associated risks. Both methods require the leads to be channeled under the skin and connected to the pulse generator. The generator is surgically placed in a subcutaneous pocket formed in the left upper abdominal wall. The AICD battery is capable of delivering about 300 shocks and has a monitoring life of 4 to 5 years. The device must be noninvasively tested every 2 to 3 months during the first year post-implant and then every 1 to 2 months thereafter. This testing of the AICD pulse generator is performed to assure an active AICD mode and to test the battery life. Testing may be performed in the physician's office or clinic (Mason \& McPherson, 1992). During these visits to the physician a review of medications, history of 
interim events (presyncope, syncope, or AICD discharge) and physical examination are performed.

statement of the Problem

The AICD is no longer considered an experimental procedure. It has become a therapeutic option for the treatment of life-threatening cardiac dysrhythmias. The clinical use of the AICD has resulted in an impressive decrease in the mortality rate of the implantees. Since the Food and Drug Administration (FDA) approved the device in 1985, the number of patients receiving this device has grown exponentially. As a result, many more health professionals will come in contact with these patients. Knowledgeable health care professionals can assist these patients by preparing them and their families for what to expect following AICD implantation.

With the diagnosis of sudden cardiac death and the subsequent implantation of the AICD, patients and their families will experience certain immediate psychosocial and environmental changes. How well individuals respond to these changes is correlated to their customary ability to cope with stress. During the crisis of hospitalization, patients and their families may be concerned only with survival. In this case, it may be difficult for the health care professional to adequately assess if the patient's learning needs are being met. 
Prior to the AICD implantation, patients and their family members participate in a formal teaching session which outlines the nature of the cardiac dysrhythmia and the way in which the AICD recognizes and terminates it. The instruction is performed using patient teaching booklets, slides, and AICD generator/lead facsimiles.

The AICD patients generally receive teaching in the acute care setting preoperatively, postoperatively, and immediately prior to discharge. How much of this teaching, given during the highly stressful, critical phase of the illness, is retained, and how much is lost are questions that need to be addressed. The patient's learning in the hospital is oriented towards the hospitalization phase of the AICD implantation. After discharge more problems and questions are identified. Needs identified by the health care professional and the actual needs of the patient may vary considerably. Identifying health related learning needs that are meaningful to patients will ensure appropriate discharge teaching. Research which recognizes and anticipates post-discharge learning needs has significant implications for patients and their families, as well as for health care workers. Therefore, this study was designed to investigate what are the AICD recipients' perceptions of their learning needs after discharge from the acute care facility. 
Purpose

The purpose of this research study is to identify health related learning needs of the automatic internal cardioverter defibrillator recipient following discharge from the acute care facility.

Definition of Terms

For the purpose of this research study, the following definitions apply:

1. The automatic internal cardioverter defibrillator (AICD) is a self-contained fully automatic electrical device capable of identifying and treating life-threatening irregular heart rhythms. The AICD performs this function by first recognizing the malignant dysrhythmia and then delivering an electrical countershock until a normal rhythm is restored. This device is capable of delivering 300 shocks before the generator's lithium powered battery pack needs replacement (Mason \& McPherson, 1992).

2. Following discharge refers to a period of 2 to 16 weeks after the patient leaves the hospital and returns home.

3. Home refers to the first nonhospital residence following automatic internal cardioverter defibrillator implantation.

4. Learning needs refers to a deficit in knowledge or skills related to an existing health problem, disease 
prevention, or promotion of health (Pender, 1974).

5. Perception is a conscious awareness of objects and concepts which can be indirectly measured by seeking a person's opinions and feelings or by observing a person's behavior (King, 1968).

\section{Objectives of the Study}

The objectives of this study were to:

1. Refine and adapt a previously developed Interview Guide for the AICD population. This Interview Guide was designed to measure the health related learning needs of open heart surgery patients after they had been discharged to their homes.

2. Refine and adapt a previously developed Cardiac Patient Learning Needs Inventory (CPLNI) for the AICD population. This Inventory was designed to measure the health related learning needs of myocardial infarction (MI) patients.

3. Administer the adapted data collection tools to post-implant automatic internal cardioverter defibrillator patients 2 to 16 weeks after discharge from the hospital. 4. Identify through patient interviews any need for reinforcement of predischarge teaching.

5. Analyze the data and make recommendations regarding teaching and learning needs following automatic internal cardioverter defibrillator implantation. 
Question

What are the health related learning needs of the automatic internal cardioverter defibrillator recipient after discharge from an acute care facility?

Assumptions

An assumption held for this study is that the subjects will understand the interviewer's questions and answer accurately and honestly. It is also assumed the patients selected for this study are representative of the AICD population at this facility. Finally, this research is based on the assumption that there are health related learning needs following discharge that need to be identified.

Research Design

The research design was a nonexperimental, descriptive, survey study of the health related learning needs of automatic internal cardioverter defibrillator recipients. Participants approached for this study met the following inclusion criteria: (a) able to read, write, and speak in English; (b) at least 2 weeks and not more than 16 weeks post-implant; and (d) discharged from the acute care facility directly to their homes. Because individuals who have undergone AICD implantation are geographically dispersed, data were collected by telephone interviews from the hospital and by a mailed questionnaire. 
A modified Interview Guide and The Cardiac Patient Learning Need Inventory (CPLNI) were the data collection tools. The Interview Guide was developed by Doordan (1976) for graduate research aimed at identifying learning needs following discharge after coronary artery bypass (CABG) surgery. Tests for clarity and content validity on this instrument were performed on three pilot studies involving CABG patients (Doordan, 1976; Gallagher, 1978; Reeves, 1976). For this study, adaptations were made to the Interview Guide to increase its applicability to the AICD population (see Appendix A) .

The CPLNI was developed by Gerard (1982) for graduate research on MI patients. This tool contains a series of informational items drawn from a review of the literature recommending what information should be taught to cardiac patients. This self-administered questionnaire was grouped into eight categories: Introduction to the CCU, cardiovascular anatomy and physiology, psychological concerns, risk factors, medication, diet, physical activity, and miscellaneous information. The last category consisted of items that did not apply to the other categories of information. The questionnaire was modified for use on the AICD population (see Appendix B). For purposes of this study, the introduction to CCU category was eliminated. To ensure validity, items selected for this tool were based 
upon recommendations found in the nursing literature concerning the teaching of cardiac patients. The completed tool and instructions were reviewed by five experts in the field of cardiovascular nursing. Recommended revisions as to clarity of items, content of items covered, and directions to subjects were made as needed.

Scope and Limitations

The scope of this study was concerned with identifying health related learning needs of individuals after the surgical implantation of an AICD. The literature confirms that cardiac patients have learning needs and it is important that these reeds are recognized and identified soon after implantation.

A qualitative study involving 32 participants has limitations. A large sample size increases the possibility that the statistical data are true estimates of the population. From the sample size used in this study, it is not possible to make generalizations to the entire AICD population. In addition, random sampling was not feasible with the available patient population. Doing so would have greatly limited the sampling size.

The interview as a method of data collection also has disadvantages. The use of an interview, whether in person or by telephone, allows subjects to report data for themselves. Assumptions must be made that the subject 
understands each question, is responding truthfully, and is not influenced by any interviewer bias. However, Oyster, Hanten, and Llorens (1987) describes the interview as an extremely useful tool in collecting research data, where one may yield information that could not be collected by any other means. A disadvantage of the questionnaire is the researcher may be uncertain if responses were based on misunderstood information or questions (Oyster et al., 1987). These limitations were acceptable to the researcher because of the lack of data collection related to similar studies of $A I C D$ recipients. 
Chapter 2

CONCEPTUAL FRAMEWORK AND REVIEW OF RELATED LITERATURE

Conceptual Framework

A primary aspect in caring for the AICD patient is to determine what learning needs are important for the patient. A basic premise of this study is that patients have health related learning needs important to them that are not identified during the hospitalization and that need to be addressed soon after discharge. Today's acute care nurse must determine if basic needs are being met before attempting to progress to higher levels of learning behavior. During the acute phase of hospitalization physiologic needs such as pain relief, rest, and healing are the primary focus and learning needs become secondary.

Abraham Maslow's (1970) hierarchy of needs theory and concepts from a model of reasoned action provide the framework for studying the health related learning needs of the AICD clients. Maslow classifies human needs into five basic categories: physiological, safety, love, esteem, and self-actualization. Maslow places these needs in ascending hierarchial order, with self-actualization at the top, and physiological needs at the bottom.

Physiological needs involve such basics to survival as food, water, sleep, and sex. Safety needs involve security and the need for an orderly, familiar environment. Love 
needs include the need for affection, and the need to belong to a social group. Esteem needs include feelings of self confidence, worth, strength, achievement, independence, status, recognition, and being useful and necessary in the world. Self-actualization, the highest need in the hierarchy, is characterized by creativity, self-fulfillment, and the development of each individual's unique potential. The role played by each need in motivating a learning behavior depends upon its position in the hierarchy. Learning behaviors motivated by one of these needs' categories appears only when the needs below that category in the hierarchy have been largely met. Maslow (1970) theorizes that as the behavior from a higher needs category surfaces, the behavior from the lower needs category will no longer be the dominant behavior. This progression of motivational changes from one needs level to another proceeds through the hierarchy as long as the needs below the dominant needs level continue to be met. Regression to a lower hierarchial level will occur if lower level needs are not satisfied.

During the stressful postoperative period, successful teaching/learning situations are difficult because, as seen in Maslow's theory, other lower level needs become more dominant. The crisis of surgery affects a patient's ability to learn, while at the same time it makes the need to learn 
imperative if the patient is to receive the full benefit from the surgery. The motivation to learn and to adapt to the crisis may not occur until after discharge.

Redman (1988) defines motivation as forces acting on or within an organism to initiate, direct, and maintain behavior. Smitherman (1981) found that motivation relates to whether a client wants to learn and is usually greatest when the client is ready, the learning need is recognized, and the content is meaningful to the client. In the teaching-learning situation, motivation addresses the willingness, readiness, or ability of the learner to put energy into learning.

Fishbein and Ajzan (1980) developed a theory of reasoned action to explain the relationship between what an individual felt was important to learn and what they actually intended to do. Miller, Wikoff, McMahon, Garrett, and Ringel (1985) adapted this theory to explain the link between cardiac patients' beliefs, attitudes, and their adherence behavior. Information that was identified by the patients as important to learn was, in fact, learned and was related to positive adherence of their medical regime.

To be most effective, learning needs must be individualized according to the patient's current location on Maslow's needs hierarchy. In addition, the information the patient identifies as important to learn must be 
acknowledged. If the patient is to receive maximum benefit from the AICD, patient learning needs must be met and adherence to the medical regimen must be attained.

\section{Review of Literature}

The automatic internal cardioverter defibrillator is rapidly gaining acceptance as the treatment of choice for individuals with life-threatening cardiac dysrhythmias. These dysrhythmias make the individual prone to sudden death. Prior to the development of the AICD, such dysrhythmias would claim 400,000 to 450,000 lives annually (Lowen, 1980). Eighty percent of those patients who experience a sudden death episode die before they reach the hospital (Moser, Crawford, \& Thomas, 1989).

Since 1985 when the device was approved by the Food and Drug Administration (FDA), more than 15,000 AICD's have been successfully implanted (Mason \& McPherson, 1992). Currently, this number is doubling every 2 years as more physicians are trained and as more hospitals become equipped to deal with this new population of patients. It has been estimated that by 1997 there will be 45,000 to 75,000 AICD's implanted yearly (H. Mead, personal communication, March 1 , 1993).

The survival rate of the AICD patient with sudden cardiac death from documented ventricular tachycardia is 98 percent for the first year, dropping to only 94 percent by 
the fifth year (Cardiac Pacemakers, Inc., 1989). Evidence is documented in several studies that the device is highly successful in terminating malignant dysrhythmias and allowing individuals to return to productive, worthwhile lives (Cooper, Luceri, Thurer, \& Myerburg, 1986; Dietz, 1991; Kalbfleisch, Lehmann, Steinman, Jackson, Axtell, Schuger, \& Tchou, 1989; Pycha, Calabrese, Gulledge, \& Maloney, 1990).

With the recognized significance of effective patient teaching and patient education in health care, several studies have been done in recent years pertaining to the learning needs of different clinical populations (Gerard \& Peterson, 1984; Goddard \& Powers, 1982; Karlick \& Yarcheski, 1988; Karlick, Yarcheski, Braun \& Wu, 1990; Lauer, Murphy, \& Powers, 1982). Much of this research has been to compare patients' and nurses' beliefs regarding the importance of learning needs relative to the specific illness of the patient.

Goddard and Powers (1982), in studying the learning needs of hemodialysis patients, found that nurses assigned the highest priority in patients' learning needs to diet and fluid restriction. The highest priority for patients, however, was to learn how to prevent injury to their fistula and how to avoid infections. In a similar study of the learning needs of patients with cancer, patients felt it was 
most important to learn about their diagnosis, their plan of treatment, how to care for themselves at home or at work, and what they would experience during their procedures. Nurses felt the patients most needed to know about availability of financial assistance, how to care for themselves at home or at work, and how to talk to their families and friends about their illness (Lauer, Murphy, \& Powers, 1982).

Gerard and Peterson (1984) studied learning needs of patients with cardiac disease relative to their specific illness. Using The Cardiac Patient Learning Needs Inventory (CPLNI) they compared findings among 15 post-myocardial infarction (MI) inpatients, 15 post-discharged patients, 15 Coronary Care Unit (CCU) nurses, and 15 post-CCU nurses. This study focused on patients' and nurses' perceptions of learning needs in an effort to learn how congruent these perceptions were. In addition, patients' perceptions of the nurse-teacher as a legitimate authority in relation to the content areas for cardiac patient teaching were explored. This study found that learning needs identified by the patients were similar to those identified by the nurses. In addition, the study found that patients perceived the nurse as a legitimate authority capable of providing valuable information. This study did not focus on what were the specific learning needs identified by this population. 
In a partial replication of Gerard and Peterson's 1984 study, Karlick and Yarcheski (1988) had similar results of the major findings. This study also compared nurses' and patients' perceptions of learning needs. As in the earlier study, there was little discussion identifying specific learning needs.

Karlik, Yarcheski, Braun, and wu (1990) studied the learning needs of patients with angina. Results of this study indicated there are similarities and differences between patients and nurses in what they believe is important to learn. This study used a model of reasoned action (Fishbein \& Ajzan, 1980) to explain the link between cardiac patients' beliefs and their adherence behavior. The reasoned action model was adapted for use on a study of the learning needs of myocardial infarction patients (Miller, Wikoff, McMahon, Garrett, \& Ringel, 1985) and was used on research of the learning needs of hypertensive patients in a later study (Miller, Wikoff, \& Hiatt, 1992). Findings from both studies indicate that compliance behavior is directly influenced by intention. Pender's 1974 study of 138 hospitalized medical/surgical patients found that once immediate health needs were met, patients were ready to receive information about short or long-term adaptation to their illness. During hospitalization the cardiac patient may not feel well enough 
to learn or may be in a stage of psychosocial adaptation not conducive to learning the behaviors and knowledge they later need. According to Maslow (1970), until the basic physiological needs are met with some satisfaction, needs at a higher level will not be met.

Limited current research has been aimed at identifying learning needs after discharge from the acute care facility. In a 1972 study of coronary patients, Baden found that patients had questions and problems in the first few weeks at home that were not anticipated prior to discharge. Baden found that patients and families misinterpreted much of the teaching information received during the hospitalization. As a result of this study, Baden recommended that comprehensive group teaching sessions be given postdischarge to cardiac patients. An example was presented of a post-discharge program in which the content of the course was determined from the expressed learning needs of the patient. Sessions were devoted to topics such as anatomy and physiology of the heart, symptoms of heart disease, psychological recovery, diet, and activity. Kelsey and Beamer (1973) recommended the development of "Community Heart Clubs" whose main goal would be to educate and promote problem solving with cardiac patients. These authors advised structuring the content of the sessions around areas of interest that had been identified by group 
members at previous meetings. Content areas identified by patients were: anatomy and physiology, risk factors, and activities and limitations.

To date, a very small body of research literature exists on health related learning needs prior to and following discharge specific to the AICD population. DeBorde, Aarons and Biggs (1991) reported it was common for the AICD recipient to encounter adjustment problems specific to the AICD not always anticipated prior to discharge. Current research indicates it is imperative that health care workers who provide care for the AICD recipient recognize that successful adaptation to the device will occur if adjustment problems are identified and treated soon after implantation. Anticipating and identifying these needs will assist the patient in successfully adapting to the device. 
Chapter 3

METHOD

Research Design

This nonexperimental, descriptive, survey study focused on the health related learning needs of automatic internal cardioverter defibrillator (AICD) recipients following discharge from the acute care facility. A descriptive design was chosen due to the lack of research in the area of learning needs of the AICD recipient.

Geographically, individuals who are AICD recipients are widely dispersed, therefore, the data collection methods were by telephone interview and questionnaire. The questionnaire was distributed and returned by mail. The telephone interview was conducted shortly after the questionnaire was returned to the investigator. Because research in this area is limited, the researcher explored the health related learning needs on a select group of AICD recipients. No attempt was made to manipulate variables or to establish causal relationships.

Subjects

The subjects who participated in this study were a convenience sample of 32 AICD recipients. These patients were part of a population made accessible to the researcher through referrals from a Bay Area electrophysiology medical group. The criteria used for selecting the sample were AICD 
recipients who were: (a) able to read, write, and speak in English; (b) at least 2 weeks and not more than 16 weeks post-implant; and (c) discharged from the acute care facility directly to their homes. The subjects were randomly selected among the AICD population who met the above criteria. Men and women were not necessarily represented equally. No subjects were excluded on the basis of age or previous health status. Before initiation the study was reviewed and approved by the subjects' physicians and the San Jose State University Institutional Review Board. The hospital's Institutional Review Board did not require review or approval since the subjects were not approached until after discharge and no medical records were utilized by the researcher.

Patients qualifying as subjects were contacted after discharge by telephone and asked if they would participate in the study. Those patients that agreed to participate in the study were sent a questionnaire with instructions to return it to the researcher in a self-addressed stamped envelope. Those patients returning completed questionnaires were the subjects for this study.

Instruments

Two instruments were used to study the health related learning needs of AICD recipients: a personal Interview Guide and the Cardiac Patient Learning Need Inventory 
(CPLNI). The personal Interview Guide was developed by Doordan (1976) for graduate research aimed at identifying learning needs following discharge after coronary artery bypass ( $C A B G$ ) surgery. Tests for clarity and validity on this instrument were performed on three pilot studies involving CABG patients (Doordan, 1976; Gallagher, 1978; Reeves, 1976). For this study, the Interview Guide was adapted for use on the AICD population (see Appendix A). The Interview Guide was originally used as a face-toface interview with direct contact with respondents. Because of the relatively large sample size and the geographically dispersed population involved in this study, the researcher chose to use the Interview Guide as a mailed questionnaire. Constructed with open-ended questions, the Interview Guide enabled the patients to be unrestricted in their responses and to avoid "yes" and "no" answers. Openended questions are particularly useful when dealing with complex information where nuances might be lost by forcing subjects to respond to predefined answers (Oyster et al., 1987). The order of questions went from general to specific. Beginning questions addressed broad problems or concerns. Later questions were more specific and individualized. The last question allowed the subject to address any concern or problem they may have encountered since discharge. 
The CPLNI (Gerard, 1982) was first used in an unpublished masters thesis studying learning needs of cardiac patients. This instrument contains 43 items which patients and nurses were asked to rate on a scale from 1-5, from "not important" to "very important." Information contained in the CPLNI was grouped into eight categories: Introduction to the Coronary Care Unit (CCU), Cardiovascular Anatomy and Physiology, Psychological Concerns, Risk Factors, Information about Medications, Dietary Information, Physical Activity Information, and Miscellaneous Information. The coefficient alpha indicating reliability for the entire test was .91. Alpha coefficients for each informational category were as follows: Introduction to CCU, .68; Anatomy and Physiology, .96; Psychological Concerns, .69; Risk Factors, .86; Medications, .89; Dietary Information, .89; Physical Activity, .81; and Miscellaneous Information, .84 (Gerard \& Peterson, 1984). Because this study focused on discharged patients, the category on "Introduction to $\mathrm{CCU}$ " was omitted.

The CPLNI questionnaire was adapted with permission of the author for use on the AICD population for this study (see Appendix B). In order to ensure content validity, many items included were based on a review of the literature. Items and instructions were also judged for clarity by three master's prepared cardiovascular specialists who work 
primarily with AICD clients. Revisions were made as recommended to clarify items, change wording, and improve instructions.

\section{Data Collection Procedures}

Permission for this study was obtained from the Human Subjects Institutional Review Board at San Jose State University (see Appendix C). An additional letter was obtained for authorization from the electrophysiology physician group at the sample site (see Appendix D). All qualified subjects were telephoned, given a brief description of the study, and asked if they would be willing to participate. Those patients who agreed to participate in the study were mailed a questionnaire (the CPLNI and the Interview Guide) and a cover letter with instructions to return it to the researcher in a self-addressed stamped envelope. The cover letter explained the research and emphasized the importance of cooperation. It also expressed gratitude to the subjects for their participation (see Appendix E). In addition, a letter of consent (see Appendix F) was mailed to all participants. This letter assured the participant's anonymity and informed them of their right to withdraw from the study at any time.

Two weeks following the initial mailing a follow-up telephone call was made to potential subjects who had not returned their questionnaires. At that time the individuals 
were asked if they intended on completing the questionnaire. A further explanation of the importance of the study and a review of the Patient's Bill of Rights were given at that time. Thirty-two ( $86.5 \%$ ) of the 37 potential subjects responded by returning a completed questionnaire. An additional questionnaire was received after data analysis was complete, and this questionnaire was discarded.

Sixteen of the 32 subjects were chosen randomly for telephone interviews. Numbers were assigned to each subject and placed in a hat. The first 16 numbers drawn from the hat became the subjects to be interviewed by telephone. One individual declined to be interviewed. The remaining 15 subjects were asked the question, "From your experience, when do you think teaching should take place for optimum learning to occur." Descriptive data obtained from these conversations are presented along with the findings in Chapter 4 .

The identity of the participants was protected with each telephone interview or questionnaire being numerically coded by the researcher. The data was transferred to computer disks and kept in a locked file accessible only to the researcher directly involved in this project.

At the end of data collection, the scores were tabulated and statistical analysis was completed. The responses to each question were categorized by type and 
analyzed according to frequencies and percentages. Recommendations were made according to the results. In summary, this research study was designed to identify health related learning needs of the AICD recipients using a convenience sample referred to the researcher by professional contacts. A mailed questionnaire and a personal telephone interview were used to collect data. Questions related to learning needs were developed to focus on concerns of the AICD patients and on general areas that were identified in the literature as patients' concerns and problems. 
Chapter 4

FINDINGS

This chapter describes the health related learning needs of 32 automatic internal cardioverter defibrillator (AICD) recipients as measured by a questionnaire which included the Cardiac Patient's Learning Needs Inventory (CPLNI) and the Interview Guide. The data were grouped and analyzed according to the general categories suggested by the two instruments. The intent was to identify health related learning needs of AICD recipients after their discharge from the acute care facility. Some specific comments made by the recipients were listed to demonstrate particular problem areas more clearly.

The results of this study are presented in the following order: (a) description of the Interview Guide responses; (b) description of the CPLNI responses; and (c) description of the telephone interviews.

Interview Guide Responses

Responses to the open-ended questions of the Interview Guide were converted into a data form suitable for analysis through the process of open coding using key words and phrases to categorize data. Data were divided into two distinct categories: learning need related data and nonlearning need related data. The data were described in tabular graphic and narrative form. The analysis of the 
responses showed that patient concerns fell into three categories: (a) general health related progress, (b) physical activity and limitations, and (c) fears, anxieties, or anger. Learning needs were often inferred from the concerns expressed in the Interview Guide, rather than being directly stated.

General Health Related Progress

The first question was an introductory open-ended question which asked how the AICD recipient had been feeling generally since discharge from the acute care facility. The recipients identified the broader and more general problems and concerns they encountered once home from the hospital. Responses often denoted more than one major concern or problem. Therefore, it was sometimes unclear as to whether a problem was the cause or genesis of the other problems. For example, if a subject's constant discomfort caused him/her to be depressed, the researcher chose whether discomfort or depression best expressed the individual's dominant feeling about their general health. Table 1 shows the categories of responses to this question.

Twelve percent said they were feeling well and had no major problems. One subject reported, "I am relaxed and I feel secure in the AICD as my lifeline. It has given me reassurance and I feel good about that." Nineteen percent $(\underline{n}=6)$ of the recipients stated they were moderately to 
severely depressed since having the AICD implanted. One individual stated, "Basically at this point our lives are a mess, our sleeping patterns are lousy, our sex life is shot. In short, our whole life is different." Four subjects cited frequent episodes of forgetfulness as the primary reason for their depression.

Table 1

General Health Related Progress $(\mathrm{N}=32)$

General Feeling 므(\%)

Feeling well, no problems $4(12 \%)$

Feeling moderately to severely depressed $6(19 \%)$

Feeling tired all or most of the time $9(28 \%)$

Feeling physical discomfort all

or most of the time $13(41 \%)$

Twenty-eight percent of the subjects stated they were constantly either tired, fatigued, weak, or they had no energy. Many subjects wanted to know if this was normal, and if so, how long should they expect it to last. One subject stated, "I'm experiencing extreme tiredness, no energy, physical weakness especially in my legs. I wish I felt better. I thought after the heart surgery I would have more strength." 
Forty-one percent of the subjects felt that pain and discomfort, either from the surgery or from the device itself, was a major problem. This problem contributed to loss of sleep, lack of sex drive, depression, and inability to exercise. Of this group of 13 subjects, five men and one woman stated the device was situated around their waist in such a way that they could no longer wear belts. The recipients were able to find solutions to some of these problems by choosing to wear suspenders, loose fitting clothing, or have their wardrobes altered. One woman stated, "I discovered I needed a support garment around my abdomen, even to sleep--seems to prevent unit's movement." One individual reported he now had to sit in a stretched-out angle so the device would not press on his ribs. Another person commented it would have helped him adjust if, "Perhaps I had received more information about the size of the AICD--and the bulge it creates at the waistline." Another reported, "The metal box of the AICD irritates the area around my body's midsection. Muscles, nerves, tissue, or whatever, none of my doctors has diagnosed and/or treated my problem. I must learn to live with it and help myself as best I can." It was reported by 15 subjects that these were unexpected problems for which they had not been prepared.

The majority of responses to the question of how things had been going since the recipient's discharge from the 
acute care facility were categorized as negative or nonfavorable. Only four subjects reported they were generally doing well, and their progress was perceived as good. The overwhelming remainder of subjects (88\%) expressed concerns or questions regarding their general progress. These concerns or questions, whether physical or emotional, represent learning needs that need to be addressed.

Anxieties, Fears, or Anger Question number six on the Interview Guide asked the subjects if they had any fears concerning their AICD. Table 2 shows the general responses to this question. Table 2

Expressed Anxieties, Fears, or Anger $(\mathrm{N}=32)$ $\underline{n}(\%)$

No Expressed Anxieties, Fears, or Anger

Expressed Anxieties or Fears $15(47 \%)$

Expressed Anger

$4(12 \%)$

Thirteen of the respondents (41\%) stated they had no fears concerning their AICD. Fifteen recipients (47\%) directly expressed fears or anxieties concerning their AICD. These subjects reported lack of information, physical and emotional problems, and role changes as reasons associated 
with these fears and anxieties. Specifically, fears expressed were the fear of pain should the defibrillator go off and the individual would be shocked, or the fear that the defibrillator would not go off when needed. Three subjects were afraid the defibrillator might mistakingly discharge during normal activities or exercise. All of these problem areas represent learning needs, although the subjects did not always identify them as such.

Four subjects (12\%) expressed anger to some degree. One recipient found out through a medical newsletter that the first device she had implanted had been recalled. She stated, "First AICD \#1500 failed 11-9-92, resulting in revision \#1625 1-14-93. \#1500 recalled as Class I risk (highest). I learned this NOT from my doctors, but enclosed newsletter." Another subject citing a similar experience said, "None of the doctors or hospitals informed me of a defect in my first AICD. They only confirmed the defect after I received a letter from the 'Implanted Device Registry' (to which you have to be a paying member). The manufacturer of the AICD never contacted me either." Another subject stated, "When released from the hospital they gave me a magnet. However, when I had my AICD checked in Boston for the first time the technician was alarmed that they gave me a magnet. I shouldn't have been given one. I didn't know then that the magnet could deactivate my 
defibrillator." In all four subjects, anger was associated with perceived lack of information. Of this group, $50 \%$ stated they had a good understanding of the way their AICD functions, but all four felt they needed more information. Table 3 shows the recipients reasons for their anxieties, fears, or anger.

Table 3

Reasons for Anxieties, Fears, or Anger $(n=19)$ Problem Expressed

Patients Expressing Problems

Lack of Information $12(63 \%)$

Potential or Actual Pain or Discomfort 6(32\%)

Depression

$6(32 \%)$

Lack of Confidence in Device

$4(21 \%)$

Role Change

$2(10 \%)$

Financial Burden

$1(5 \%)$

In summary, the majority of the subjects (59\%) expressed some degree of fear, anxiety, or anger. Of this group of subjects, 58\% did not feel as though they had a good understanding of how their AICD functioned. Forty-one percent of the recipients expressed no anxieties, fears, or anger. All of the recipients who perceived their general health as good were in this group. In addition, $84 \%$ of this group of subjects felt they had a good understanding of how 
their AICD functioned.

Activity and Limitations

Question number seven on the Interview Guide asks the subjects what questions they have regarding activities since they have been home. Prior to discharge, AICD recipients are told to use themselves to gauge the amount of activity they should attempt once they return home. The recipients are instructed to pace their activity and exercise according to their individual tolerance and to rest when tired or short of breath. Driving a car, lifting heavy objects, and strenuous exercise are all prohibited upon discharge. Table 4 shows the categories of responses to this question. Table 4

Concerns Regarding Exercise/Activity $(\mathrm{N}=32)$ Area of Concerns $\underline{\mathrm{n}}(\%)$

No concerns regarding exercise/activity $15(47 \%)$

Confused or concerned about limitations

Driving

Restricted exercise due to fatigue

Other (Altitude, swimming)

Forty-seven percent ( $\underline{n}=15)$ had no questions concerning activities and limitations. These individuals "use common sense," "let my body tell me what I can do," "do whatever I 
please," or "do whatever I want until I get tired." The remaining $53 \%$ of the subjects had concerns or questions regarding activities or limitations.

of the 15 subjects who had questions or concerns regarding exercise or activity, 10 subjects (67\%) were concerned or confused about their physical limitations. Subjects had questions as to the type and amount of activity or exercise that was advisable. One subject asked, "When can I get back to my normal way of living--such as gardening, long walks, driving, painting inside my home, etc. Very little was explained to me regarding limitations and activity, exercise, etc." Another patient said, "I seem to be on my own in regards to exercise." Another subject asked, "I wonder if physical therapy should be had [ $\underline{\text { sic] }}$ to help increase successful physical recovery. Does not seem to be a concern by doctors."

Five subjects (33\%) felt their activity was limited because of weakness or fatigue. Two of these subjects wanted to know when they could resume driving. One subject stated, "When can I drive? I still can't walk too far as legs tire easily." This group of five subjects had all attempted some form of exercise on their own since returning home from the hospital. All expressed a need to know when they would regain their normal energy level so they would be able to resume their usual everyday activities. 
Cardiac Patient's Learning Needs Inventory Responses

The purpose of the CPLNI questionnaire was to define and rank the AICD recipients' perceptions of their learning needs. The AICD recipients were asked to rate 37 informational items as to the degree of importance each question had for themselves as patients with heart disease. Choices ranged from (1) designating not important to (5) designating very important. A mean score was calculated for each patient by categories. The higher the score, the more important the information contained in this category. With few exceptions, the AICD recipients ranked the items in the CPLNI as at least moderately important information for them to know. Eighty-four percent of the questions were ranked by the AICD recipients as important or very important information for them know.

The category on medication information was given the highest rating by the AICD recipients (4.41 mean score). The subjects ranked this category as including information that was most important for them to learn. The other categories in order of importance to the recipient were: risk factors (4.31 mean score), activity (4.24 mean score), psychological factors (4.21 mean score), anatomy and physiology (4.17 mean score), and diet (3.94 mean score). In the activities category, the researcher asked the subjects to rank the importance of the need to know "when I 
can engage in sexual activity." The mean score on this category was tabulated with and without this question. Without this question, the mean score was 4.41 . This number is equal to the highest rating of information important to know by the subjects on all categories. With this question included, activity information ranked third among all categories with a mean score of 4.24. A possible reason for the low score on the question regarding sexual activity is that many of the AICD patients have been chronically ill prior to their implant. It may be speculated that many of these individuals have not been sexually active in recent years.

The mean scores of the category, "other pertinent information" in the CPLNI were calculated by each individual. question. The highest ranking question the subjects felt important to know was, "when to call the doctor" (mean score 4.50). This was followed in importance by "I need to know the signs and symptoms of congestive heart failure" (mean score 4.40), and "questions related to magnetic fields and my AICD" (mean score 4.37). The questions pertaining to information on "how to take my pulse" (mean score 3.46), and "where to learn CPR" (mean score 3.37), were ranked the lowest.

In summary, the purpose of the CPLNI was to define and rank the AICD patient's perceptions of their health related 
learning needs. The fact that all categories were rated at least 3.37 indicates that AICD patients felt that all of these informational items were important for them to know. These findings support the prescriptive literature concerning what information should be taught to cardiac patients (Baden, 1972; Kelsey \& Beamer, 1973). Having knowledge of their medications, activities and limitations, and when to call the doctor, were the categories the recipients ranked the highest. Description of the Telephone Interviews Sixteen of the 32 subjects involved in this study were randomly selected by the researcher to be interviewed by telephone. All had agreed to participate in the study by returning the completed CPLNI and Interview Guide questionnaire. One individual selected declined to be interviewed by telephone.

The fifteen recipients were asked when they thought teaching should take place for optimum learning to occur. The majority of respondents $(60 \%)$ felt teaching should take place after discharge from the hospital. Of this group, $90 \%$ felt the optimum time for learning was between two and four weeks after discharge. Six individuals (40\%) felt teaching should take place prior to surgery and throughout hospitalization. No one interviewed felt optimum learning would occur shortly after surgery. One recipient stated, "I 
had too many other things to think of at the time--like making it out of the hospital."

In summary, with few exceptions, the AICD recipients ranked the items in the CPLNI section of the questionnaire as at ieast moderately important information for them to know. In addition, through the Interview Guide, questions and learning needs perceived to be important by the AICD recipients have been identified. Through telephone interviews, the optimum time for teaching and learning to occur for AICD recipients was identified as between two and four weeks after discharge. This finding is consistent with Maslow's hierarchy of need, the conceptual framework selected for this study. 
Chapter 5

CONCLUSIONS AND RECOMMENDATIONS

Discussion

The purpose of this study was to explore the automatic internal cardioverter defibrillator (AICD) recipient's perceptions of their learning needs following discharge from the acute care facility. Using a personal Interview Guide and the Cardiac Patient's Learning Needs Inventory as instruments, 32 AICD recipients were able to report for themselves what information was important for them to learn. Using telephone interviews of 15 randomly selected recipients involved in this study, a time frame was determined as the optimum time for patient teaching.

The basic assumptions for this study were: (a) AICD patients, although they were given information before leaving the hospital, would experience health related learning needs once they returned home; (b) the 32 patients would be representative of the AICD population; (c) by means of the two instruments used in this study, questions regarding their health related needs would be identified, and; (d) through telephone interviews of a random sample, the optimum time for patient teaching would be identified. These assumptions were supported by the findings.

By means of the two instruments used in this study it was determined that there are major problems and concerns 
facing these individuals. Predischarge teaching was done; however, consistent learning did not always take place. On many items, patients appear poorly informed regarding information that is necessary for their well-being. Most of this information was presented to them while they were still in the hospital. Many of the AICD recipients expressed feelings of anxiety, fear, or anger, and the majority felt these feelings were caused by lack of information. Many recipients felt they were not told everything, and that important information they were entitled to know had even been withheld.

It was reported that generalized feelings of discomfort, fatigue, or depression were common. These feelings were unexpected by the majority of the respondents. Had the AICD recipients been told in advance that these physical and emotional responses were normal and to perhaps even anticipate them, they might have been better able to deal with these feelings when they occurred.

The Interview Guide indicated the learning need most important for the AICD recipient to know was information on activities and limitations. The lack of adequate information in this area was reported by $52 \%$ of the respondents. Most of the recipients were not ready for this information until after discharge from the hospital. Prior to this time, the patients were concerned with immediate 
needs such as survival. Upon their return home, many recipients could not remember what activity guidelines had been given. A cardiac rehabilitation program, with individualized goals and outcome measurements, would assist these individuals in developing a personal exercise program once home from the hospital. In addition, a structured, monitored, program would help individuals exercise without many of the fears and anxieties that were felt when activities were first resumed after surgery.

Through the Interview Guide it was also determined there was a very high need to know when to call the doctor. This information should be given to the patient in written form in the hospital several days prior to discharge. The patients should be evaluated on an individual basis as to the understanding of the written material since this material is a beneficial tool for the patient for a review of information when the need arises.

The responses to the Cardiac Patient's Learning Needs Inventory (CPLNI) indicated patients felt it was most important to know about their medications. All of the AICD recipients reportedly were taking at least five different medications per day. Some reported taking as many as fifteen different prescription medications per day. These individuals need to know what these medications are, and why they are taking so many. When the individual's understand 
the importance of their medications they will be more compliant in their adherence behavior.

Through the telephone interview of fifteen recipients it was determined that the optimal time for patient teaching for these individuals was after discharge to their homes. None of the recipients felt learning was optimal immediately before or immediately after surgery. These results support the literature suggesting that patients must meet their immediate health needs before they are ready to receive information about short or long-term adaptation to their illness. To profit from the learning experience the patient must be ready to learn. Smitherman (1981) states it is almost impossible to teach someone something when he is not ready to learn it.

\section{Limitations}

The major limitations of this study were: (a) small sample size, (b) convenience sampling, (c) self-administered questionnaire (CPLNI and Interview Guide), and (d) lack of control over possible intervening variables. Generalizations from the study were limited by the sample size (32), and because the subjects were not screened for age, sex, education, ethnicity, or socioeconomic background. The influence of a spouse or other family member may have had an affect on the results, or even determined whether or not the subject would respond. Results may have been 
affected by concomitant illnesses, which may alter the AICD recipient's motivation to learn.

Recommendations

This study can serve as a basis for future research into the education of AICD patients. Recommendations for future research would include: (a) use of a larger sample size, distinguishing subjects by age, sex, ethnicity, and socioeconomic background, (b) exploring the nurses timing of when various educational information should be presented, (c) investigating patient's preferences for being taught certain information at certain points in their recovery, (d) measuring the AICD recipients learning needs at six months, one, and two years for information on possible long-term learning needs of this population, (e) use of other instruments in conjunction with those used in this research for greater validity testing, (f) comparing the health related learning needs of AICD recipients enrolled in a structured Cardiac Rehabilitation program with those not enrolled in such a program and, ( $g$ ) controlling for the possible effect of the various degrees of iliness of the AICD recipients by separating subjects into illness groups using the New York Heart Association's Functional Classification System (Underhill, Woods, Sivakajan, \& Halpenny, 1982, p. 152)

With the recognized limitations of this study, and 
based on the data elicited, the following nursing interventions are recommended:

1. Patient teaching should be individualized. Specific needs of the patient, including personal as well as medical needs must be assessed. A teaching program should allow learning to take place at a time when it is most meaningful to the learner.

2. Begin teaching in advance of surgery and provide enough teaching opportunities so that each patient can learn at his own rate.

3. Provide follow-up teaching at home utilizing community health resources. For many, optimum learning will occur after discharge. It is not until this time that many of the AICD recipients will be ready to learn the information necessary for a successful transition home.

4. Encourage participation in a Cardiac Rehabilitation program soon after discharge to develop an exercise program and to avoid many of the fears and anxieties related to activities and limitations.

5. Encourage participation in support groups for AICD recipients and their families as a method of providing ongoing educational and emotional support.

6. Provide detailed written information on all aspects of the AICD patient. This information should be available prior to surgery and remain with the patient throughout the 
hospitalization. In this way, the AICD patient could review the information that is meaningful to them when the need arises.

7. Teach information that is meaningful to the patient. According to Orem (1980) successful patient education requires knowledge of the perceived needs of the patient. It must be determined what information is perceived by the patient as important to learn.

8. The role of the nurse in the continuity of care needs to be explored. Ideally, a teaching program designed to include home follow-up throughout the entire first month after discharge should be designed. This type of program would allow individual needs to be met, and permit learning to take place at a less stressful time that may be more meaningful to the patient. During this time, patients should identify their own learning needs. The needs identified by the learner should have the highest priority. These will be the most meaningful to the learner. Automatic internal cardioverter defibrillator recipients face many changes in their lifestyle with which they must learn to cope. Knowledge of these changes and reasons for them are important factors in determining patients' successful adaptation to the device. This study has provided information on the perceived health related learning needs of these patients. This knowledge is 
necessary to maximize the effectiveness of patient education. 
REFERENCES 
References

Baden, C. (1972). Teaching the coronary patient and his family. Nursing Clinics of North America, 7, 423-430. Cardiac Pacemakers, Inc. (1989). Caring for patients with the AICD: Automatic cardioverter defibrillator systems. St. Paul, MN: Author. Cooper, D. K., Luceri, R. M., Thurer, R. J., \& Myerburg, R. J. (1986). The impact of the automatic implantable cardioverter defibrillator on quality of life. Clinical Progress in Electrophysiology and Pacing, 4. 306-309. DeBorde, R., Aarons, D., \& Biggs, M. (1991). The automated implantable cardioverter. AACN Clinical Issues in Critical Care Nursing, $\underline{2}(1), 170-177$. Dietz, D. (1991). Quality of life in automatic implantable cardioverter defibrillator recipients. Unpublished master's thesis, San Jose State University, San Jose, CA. Doordan, A. (1976). Identification of needs of coronary artery bypass surgical patients following discharge from a medical center. Unpublished master's thesis, San Jose State University, San Jose, CA.

Fishbein, M., \& Ajzan, I. (1980). Fishbein model of reasoned action. Englewood Cliffs, NJ: Prentice Hall. Gallagher, M. T., (1978). Identification of health related needs of the coronary artery bypass surgical patient following hospital discharge. Unpublished master's 
thesis, San Jose State University, San Jose, CA.

Gerard, P. S. \& Peterson, L. M. (1984). Learning needs of cardiac patients. Cardiovascular Nursing, 20 (2), 7-11.

Gerard, P. S. (1982). Cardiac patient learning need inventory (CPLNI). Unpublished work.

Goddard, H. A. \& Powers, M. J. (1982). Educational needs of patients undergoing hemodialysis: A comparison of patient and nurse perceptions. Dialysis and Transplantation, 11, 578 .

Hillis, L. D., Firth, B. G., Winniford, M. D., \& Willerson, J. T. (1988). Manual of Clinical problems in cardiology (3rd ed.). MA: Author. Hurst, J. W., \& Schlant, R. C. (1990). The heart, arteries and veins. New York: McGraw-Hill.

Kalbfleisch, K. R., Lehmann, M. H., Steinman, R. T., Jackson, K., Axtell, K., Schuger, C. D., \& Tchou, P. J. (1989). Reemployment following implantation of the automatic cardioverter defibrillator. American Journal of Cardiology, 64, 199-202.

Karlik, B. A., \& Yarcheski, A. (1988). Learning needs of cardiac patients: A partial replication study. Heart \& Lung, 16, 544-551.

Karlik, B. A., Yarcheski, A., Braun, J., \& Wu, M. (1990). Learning needs of patients with angina: An extension study. Journal of Cardiovascular Nursing, 4 (2), 70-82. 
Kelsey, H., \& Beamer, V. L. (1973). A post-hospital education program. Heart \& Lung, $\underline{2}$, 512-514.

King, I. (1968). A conceptual frame of reference for nursing. Nursing Research, 17, 27-32.

Lauer, P., Murphy, S. P., \& Powers, M. J. (1982). Learning needs of cancer patients: A comparison of nurse and patient perceptions. Nursing Research, 31, 11.

Lowen, B. (1980). Cardiovascular collapse and sudden death. In E. Braunwald (Ed.), Heart disease (p. 788). Philadelphia: W. B. Saunders.

Maslow, A. (1970). Motivation and personality (2nd ed.). New York: Harper \& Row.

Mason, P., \& McPherson, C. (1992). Implantable cardioverter-defibrillator: A review. Heart \& Lung, 21, 141-147.

Miller, P., Wikoff, R. L., McMahon, M., Garrett, M. J., \& Ringel, K. (1985). Indicators of medical regimen adherence for myocardial infarction patients. Nursing Research, 34, 268-272.

Miller, P., Wikoff, R. L., \& Hiatt, A. (1992). Fishbein's model of reasoned action and compliance behavior of hypertensive patients. Nursing Research, 41(2), 104109 .

Moser, S., Crawford, D., \& Thomas, A. (1989). Caring for patients with implantable cardioverter defibrillators. 
Critical Care Nurse, $\underline{8}(2), 52-65$.

Orem, D. E. (1980). Nursing concepts in practice. New York: McGraw-Hill.

Oyster, C. K., Hanten, W. P., \& Llorens, L. A. (1987). Introduction to research. Philadelphia: Lippincott. Pender, N. J. (1974). Patient identification of health information received during hospitalization. Nursing Research, 23, 262-267.

Pycha, C., Calabrese, J. R., Gulledge, A. D., \& Maloney, J. D. (1990). Patient and spouse acceptance and adaptation to implantable cardioverter defibrillator. Cleveland Clinic Journal of Medicine, 57(5), 441-444.

Redman, B. K. (1988). The process of patient education. St. Louis: Mosby. Reeves, S. (1976). Identification of posthospital learning needs of open heart surgery patients. Unpublished master's thesis, San Jose State University, San Jose, CA. Smitherman, C. (1981). Nursing actions for health promotion. Philadelphia: F. A. Davis. Teplitz, L. (1991). Nursing diagnosis for the automatic implantable cardioverter defibrillator patients. Dimensions of critical care nursing, 10, 188-201. Underhill, S. L., Woods, S. L., Sivakajan, E. S., \& Halpenny, C. J. (1982). Cardiac Nursing. Philadelphia: J. B. Lippincott. 
APPENDIX A

The Interview Guide 
Instructionst Please answer the following questions:

1. How have things been going since you have come home from the hospital? Do you have any specific problems? (Please use the back of this paper for additional space, if needed).

2. Do you have a routine or process that you use everyday for checking symptoms that can alert you to problems with your AICD? (Temperature check, pulse check, daily weight). Have you called your doctor about any of these things?

3. What are the medications that you were given on discharge irom the hospital? Do you have any questions regarding these medications? (Action, dosage, side effects, precautions). Are there any additional pills that you are iaking?

4. What is the diet your doctor recommended? Do you have any problems, questions, or concerns following the diet now that you are home? (Shopping, preparation of meals). Co you have any concerns about following this diet when dining away from home? 
5. Do you feel that you have a good understanding of how your AICD works? Could you briefly explain it to me? What special precautions have you taken because of your AICD? (Avoiding magnetic fields, exercise or activity limitations, clothing restrictions). Do you have any fears concerning your AICD?

6. Have you received a shock from your AICD since your discharge from the hospital? If so, can you tell me what happened and specifically what you did? How did you feel after this experience?

7. What questions do you have about your activity now that you are home?

8. Is there any additional information that we could have given you that would have helped you with any other problem or concern since your discharge from the hospital?

9. Is there anything else we have not discussed that is of concern to you now that you are home? 


\section{APPENDIX B}

The Cardiac Patient Learning Needs Inventory 

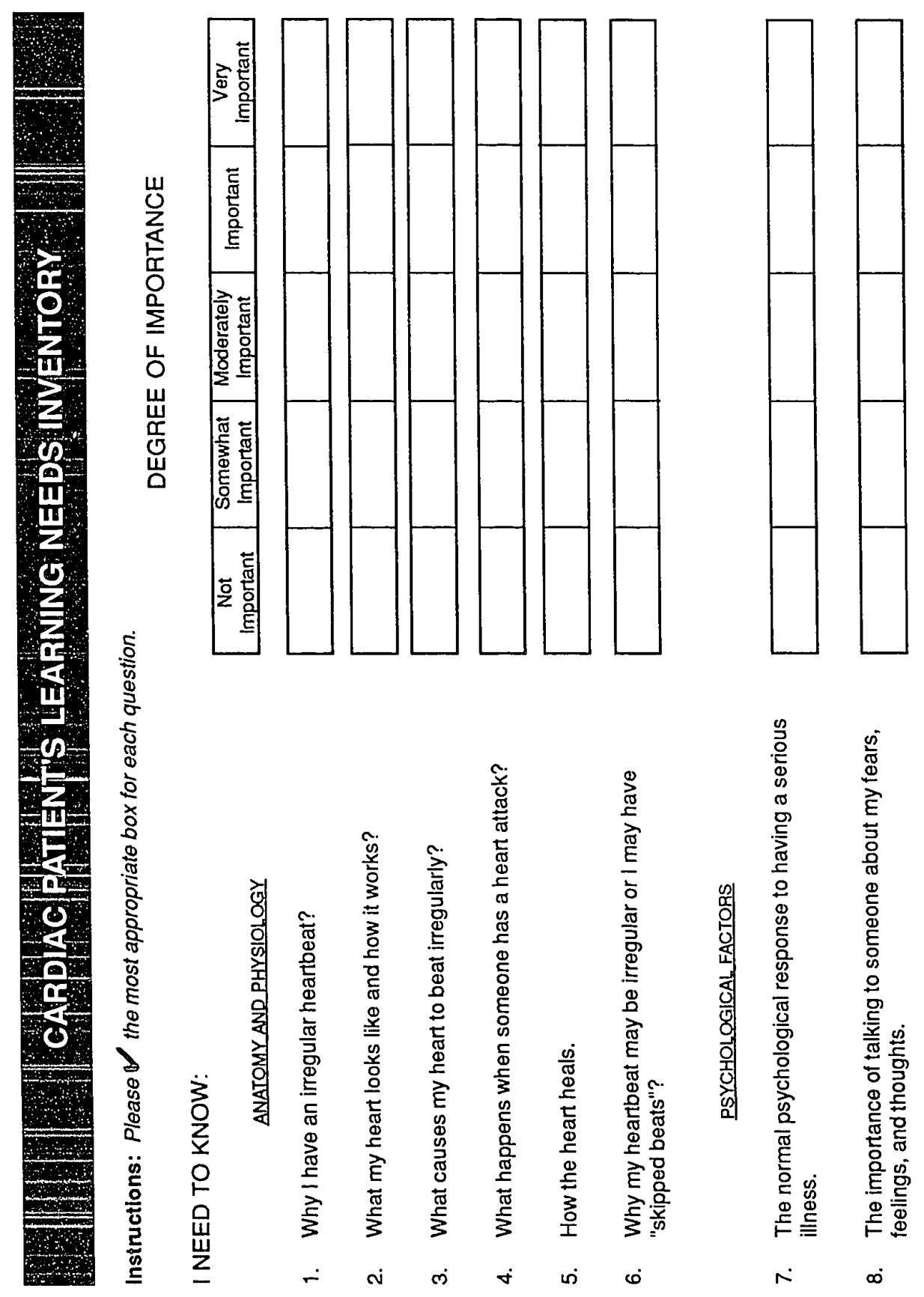

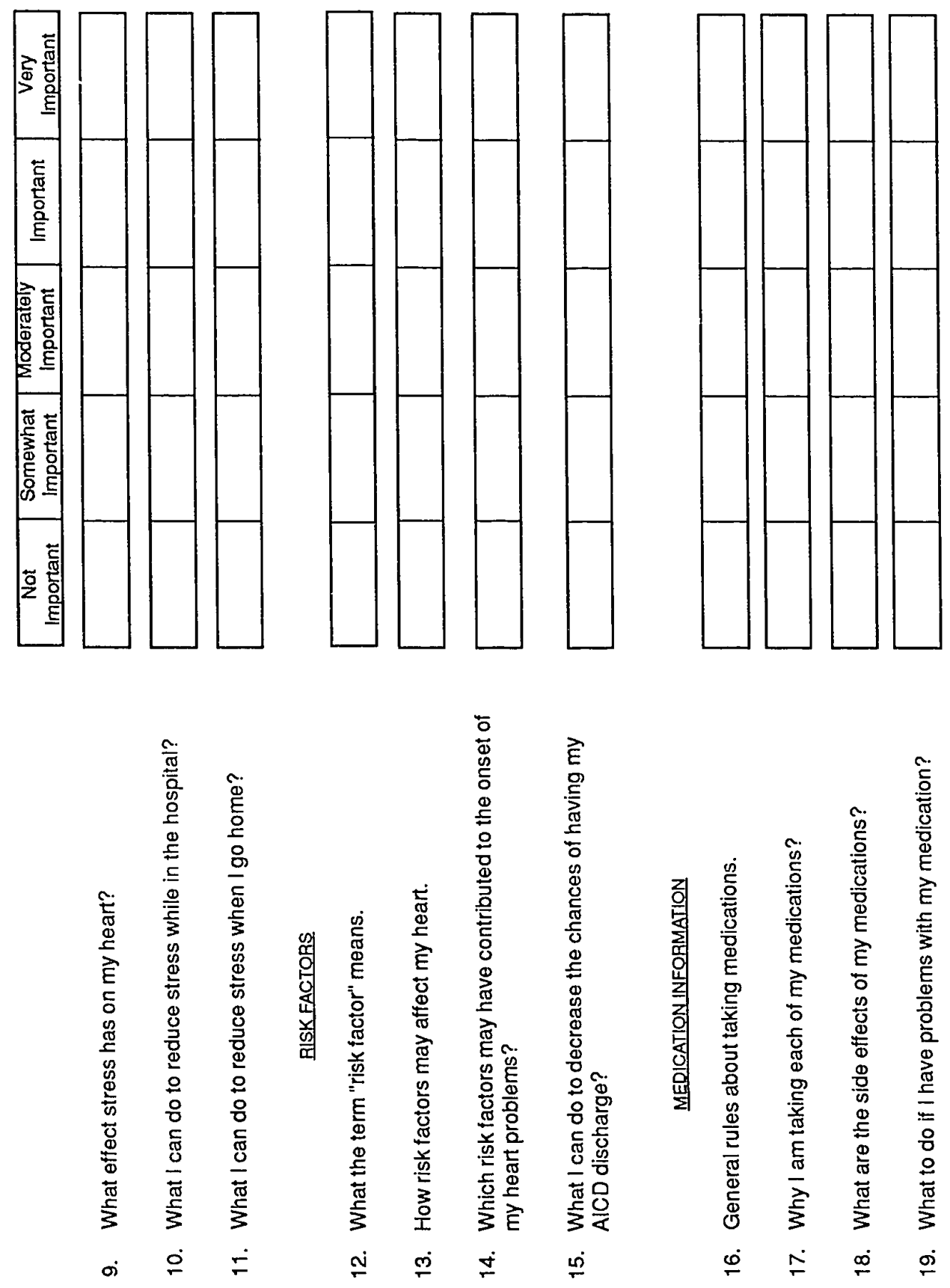

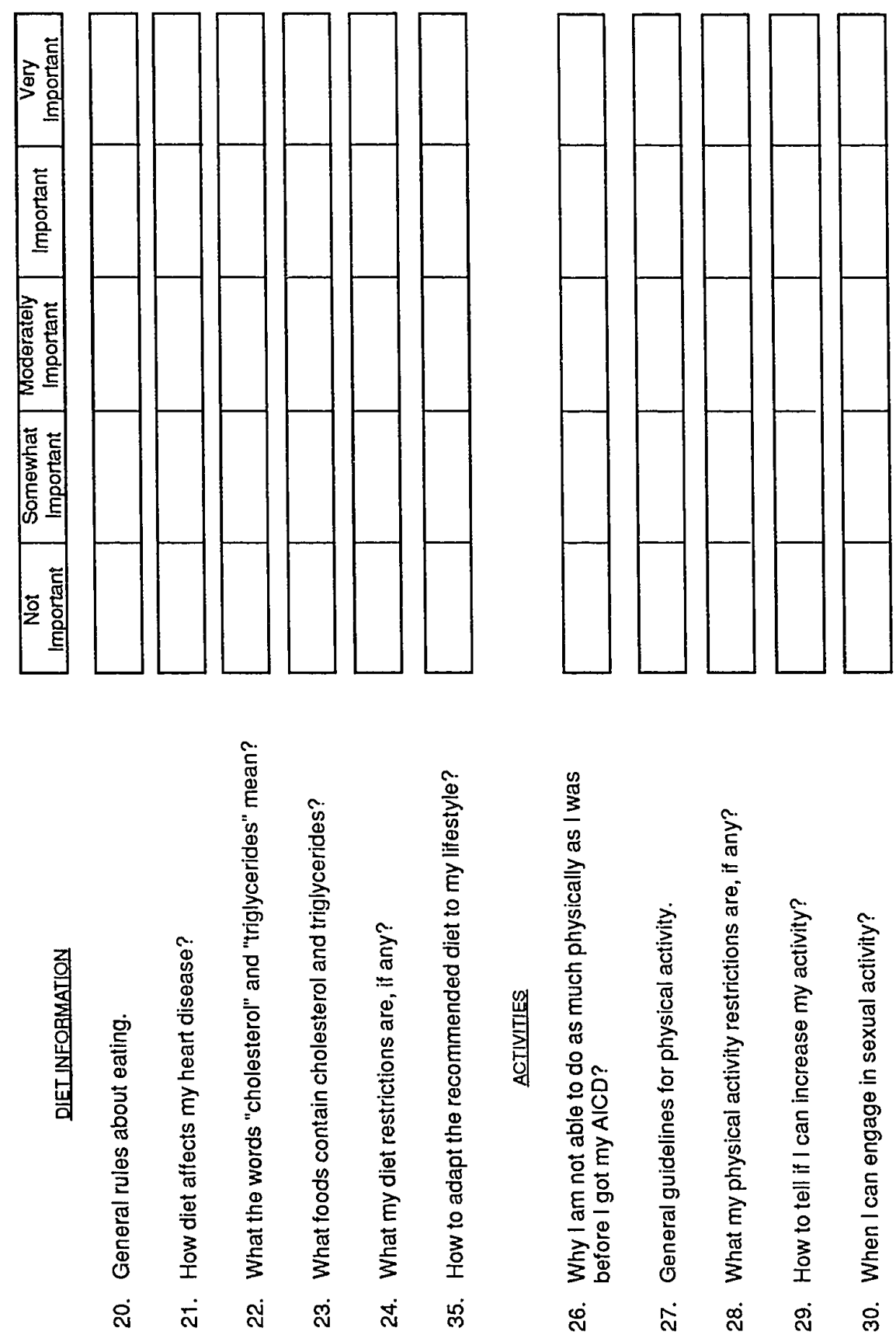

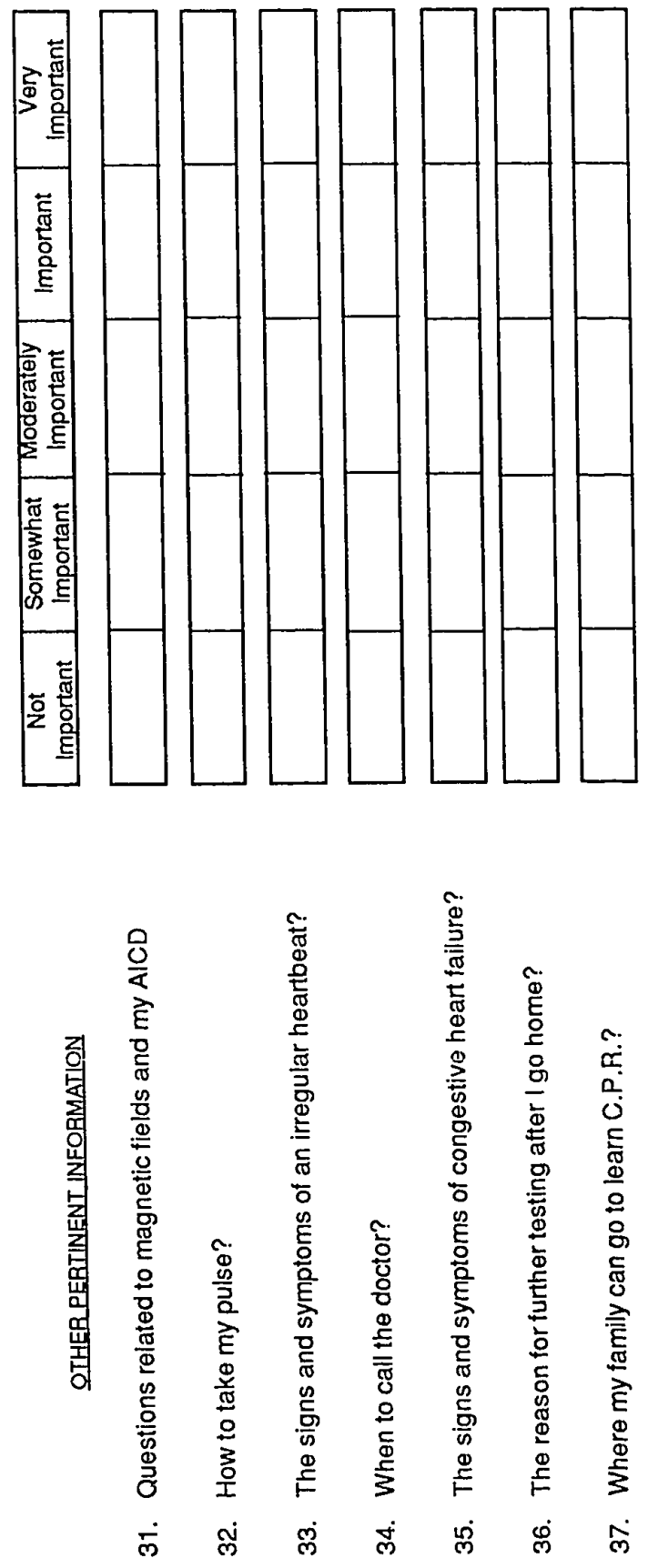
APPENDIX C

Human Subject Institutional Review Board San Jose State University 
To: Laura Val

2922 Miles Drive

Santa Clara, CA 95051

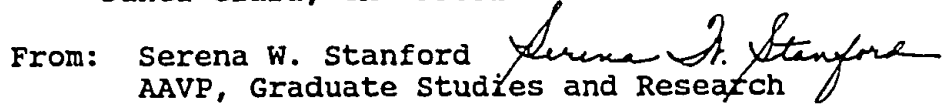

Date: April 29, 1993

The Human Subjects-Institutional Review Board has approved your request to use human subjects in the study entitled:

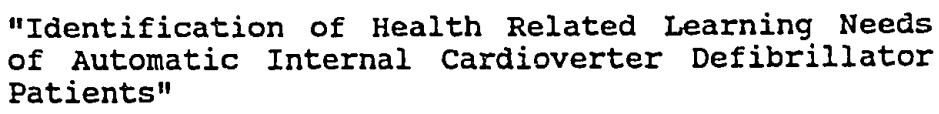

This approval is contingent upon the subjects participating in your research project being appropriately protected from risk. This includes the protection of the anonymity of the subjects' identity when they participate in your research project, and with regard to any and all data that may be collected from the subjects. The Board's approval includes continued monitoring of your research by the Board to assure that the subjects are being adequately and properly protected from such risks. If at any time a subject becomes injured or complains of injury, you must notify Dr. Serena stanford immediately. Injury includes but is not limited to bodily harm, psychological trauma and release of potentially damaging personal information.

Please also be advised that each subject needs to be fully informed and aware that their participation in your research project is voluntary, and that he or she may withdraw from the project at any time. Further, a subject's participation, refusal to participate or withdrawal will not affect any services the subject is receiving or will receive at the institution in which the research is being conducted. If you have questions, please contact me at 408-924-2480.

\section{CC: Terry Miller}


APPENDIX D

Authorization From Physician Group 


\section{Cardiovascular Medicine and Cardiac Arrhythmias}

A Portnership of Incopporated Medical Groups

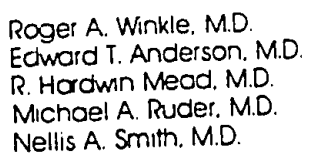

April 6, 1993

To Whom it May Concern:

Re: Learning Needs of AICD Patients Following Discharge From Hospital

This letter is written in support of the above named research project which will This letter is written in suppor The of fice of Cardiovascular Medicine and Cardiac be carried out by Laura Val. The office of Cardociplents to Ms. Val to assist Arrhythmias has given a list of names of AICD recipients to Mr. out this study.
her in her research. She has our support and approval to carry out

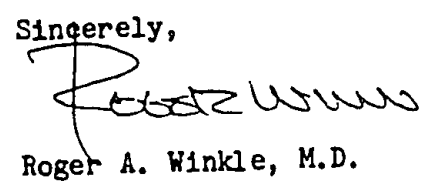

RAW : gr 
APPENDIX E

Cover Letter 
March 10, 1993

Dear

Thank you for agreeing to answer the enclosed questionnaire!

As I explained in cur phone conversation, I am a student at San Jose State University working towards a Master of

Science Degree in Nursing Administration. For my thesis I am doing a study of the health related learning needs of the Automatic Internal Cardioverter Defibrillator (AICD)

patients. By means of the enclosed questionnaire I hope to determine if there are any learning needs that you may have identified since your AICD was implanted.

Your physician, Dr. Roger Winkle, supports my efforts in this project. The findings of this study will help provide the health care professionals with a greater understanding of the AICD experience and will facilitate patient care planning.

The enclosed questionnaire should take less than 30 minutes of your time. I've also enclosed a stamped self-addressed envelope for your convenience. I'd appreciate having this questionnaire returned by March 15, 1993, if possible.

You may be assured of complete confidentiality. The questionnaire has an identification number for mailing purposes only. This is so that I may check your name off the mailing list when your questionnaire is returned. Your name will never be placed on the questionnaire.

I appreciate your assistance in completing this project. It has been designed to help AICD patients like yourself, and the health care workers that are involved in their care. If you would like a copy of the abstract when the study is complete or have any questions, please feel free to contact me. Thank you for your participation.

Sincerely,

Laura Val, RN, BSN 
APPENDIX $F$

Letter of Consent 
College of Applled Sciences and Arts - Department of Nursing

One Washington Square • San José. Calitornia 95192-0057 • 408/924-3130 • FAX 408/924-3135

AGRBEMIENT TO PARTICIPATE IN RESBARCH

SAN JOSE STATE UNIVERSITY

RESPONSIBLE INVBSTIGATOR: Laura J. Val

TITLE OF PROTOCOL: Identification of Health Related Learning Needs Following Automatic Internal Cardioverter Defibrillator Implantation

I have been asked to participate in a research study that is investigating learning needs of AICD patients. The results of this study should help health care professionals to gain a fuller understanding of the AICD experience.

I understand that

1) I will be asked to complete an 46-item questionnaire. It should take me less than 30 minutes to complete. I will return it to the primary investigator within 1 week.

2) there are no anticipated risks to me in this study.

3) there are no discernible benefits to me, however the results may benefit future AICD patients.

4) the results from this study may be published, but any information from this study that can be identified with me will remain confidential and will be disciosed only with my permission.

5) any questions about my participation in this study will be answered by Laura J. Val, (408) 985-0643. Complaints about the procedures may be presented to Dr. Bobbye Gorenberg, Department of Nursing, Graduate Advisor, (408) 924-3134. For questions or complaints about research participants' rights contact Serena Stanford, Ph.D., Associate Academic Vice President for Graduate Studies ((408) 924-2480).

6) my consent is given voluntarily with no coercion. I may refuse to participate, and I may withdraw at any time.

MY SIGNATURE INDICATES THAT I HAVE. READ THB INFORMATION GIVEN ABOVE AND THAT I HAVE DBCIDED TO PARTICIPATE.

Date $\overline{\text { Participant's signature }} \overline{\text { Investigator's signature }}$ 